\title{
IncRNA HOTTIP facilitates osteosarcoma cell migration, invasion and epithelial-mesenchymal transition by forming a positive feedback loop with c-Myc
}

\author{
YANG TANG and FANG JI \\ Department of Orthopedics, Changhai Hospital, Second Military Medical University, Shanghai 200438, P.R. China
}

Received October 28, 2018; Accepted April 24, 2019

DOI: $10.3892 / \mathrm{ol} .2019 .10463$

\begin{abstract}
Homeobox A transcript at the distal tip (HOTTIP) is an oncogenic long non-coding RNA in cancer. The aim of the present study was to investigate the function and mechanism of HOTTIP in the aggressive behaviors of human osteosarcoma (OS) cells. Expression levels of HOTTIP and epithelial-mesenchymal transition (EMT) markers were determined by reverse transcription-quantitative PCR. Cell invasive and migratory abilities were evaluated in vitro using Matrigel and wound healing assays, respectively. Knockdown of HOTTIP expression was achieved by small interfering RNA-mediated silencing. Overexpression of c-Myc was accomplished by transfecting cultured cells with a c-Myc overexpression plasmid. HOTTIP was demonstrated to be upregulated in OS tissues and cell lines; knockdown of HOTTIP inhibited OS cell migration, invasion and EMT, and suppressed c-Myc expression. In addition, overexpression of c-Myc increased HOTTIP expression and enhanced OS cell migration and invasion. HOTTIP promoted cell migration and invasion by upregulating c-Myc in OS. The positive feedback loop formed by HOTTIP and c-Myc may contribute to OS progression, and HOTTIP may act as a therapeutic target for OS.
\end{abstract}

\section{Introduction}

Osteosarcoma (OS) is the most common primary malignant bone tumor frequently occurring in children and adolescents (1). Originating from mesenchymal cells, OS often results in pulmonary metastasis and has poor overall prognosis $(2,3)$. Amputation and chemotherapy are the most common treatment options for OS; however, $40 \%$ of treated patients experience tumor metastasis, which ultimately leads

Correspondence to: Dr Fang Ji, Department of Orthopedics, Changhai Hospital, Second Military Medical University, 168 Changhai Road, Yangpu, Shanghai 200438, P.R. China E-mail: antiyaya@sina.com

Key words: osteosarcoma, homeobox A transcript at the distal tip, c-Myc, migration, invasion, epithelial-mesenchymal transition to an adverse clinical outcome $(4,5)$. Therefore, it is imperative to understand the mechanisms triggering OS metastasis for the management of this disease.

Long non-coding RNAs (lncRNAs) are a group of evolutionarily conserved non-coding RNAs >200 nucleotides long with no or limited protein coding capacity (6). Based on the location and sequence, lncRNAs can be classified into five types: Sense, antisense, bidirectional, intronic and intergenic $(7,8)$. A number of previous studies have indicated that IncRNAs are involved in almost every aspect of cell biology and contribute to tumor development by various mechanisms (9-11). Although multiple lncRNAs are abnormally expressed in cancer tissues and function as potent oncogenes or tumor suppressors (12-14), only a small number of lncRNAs have had clear underlying mechanisms identified. IncRNAs are crucial for OS initiation and progression $(15,16)$. For instance, nuclear paraspeckle assembly transcript 1 , small nucleolar RNA host gene 4 and tumor protein p73 antisense RNA 1 have been identified as oncogenic lncRNAs associated with poor prognosis of patients with OS (17-19).

Homeobox A transcript at the distal tip (HOTTIP) is an lncRNA transcribed from the 5'tip of homeobox A (HOXA) locus that controls HOXA gene expression (20). HOTTIP is significantly upregulated in human cancers; it is functionally linked with carcinogenesis and represents a potential prognostic biomarker in cancer (21). The majority of studies on HOTTIP support its oncogenic roles, including promoting cell proliferation, inhibiting apoptosis and facilitating cell migration (22). Li et al (23), reported that HOTTIP was upregulated in OS, promoted cell proliferation, migration and invasion in vitro, and higher HOTTIP expression levels were associated with poor survival. HOTTIP also increased chemoresistance of OS cells (24). However, its roles and mechanisms in OS migration, invasion and epithelial-mesenchymal transition (EMT) remain unclear. Notably, HOTTIP could activate the Wnt/ $\beta$-catenin signaling pathway in OS cells (24). Since c-Myc is a vital target gene and effector of the Wnt/ $\beta$-catenin pathway, which is associated with the malignant phenotypes of OS, including migration, invasion and EMT (25), this study hypothesized that HOTTIP could also induce c-Myc expression in OS cells. Considering the previously described attributes of HOTTIP activity, it was hypothesized that HOTTIP may be involved in OS migration, invasion and EMT. 


\section{Materials and methods}

Patients and tissues. Twenty-five pairs of human OS tissues and adjacent non-tumoral tissues were obtained from patients (range, 14-28 years old; 10 male and 15 female patients) with OS who received surgical treatment at the Department of Orthopedics, Changhai Hospital, Second Military Medical University (Shanghai, China), between January 2016 and June 2017. All samples were obtained with informed consent and approved by the Ethics Committee of Changhai Hospital, Second Military Medical University (Shanghai, China). The tissues were frozen in liquid nitrogen immediately and stored at $-80^{\circ} \mathrm{C}$.

Cell culture. Human normal osteoblastic cell line hFOB1.19 and OS cell lines SaoS2, HOS, U2OS and MG63 were purchased from The Cell Bank of Type Tissue Collection of the Chinese Academy of Science or the American Type Culture Collection. HOS cells were cultured in RPMI-1640 (Gibco; Thermo Fisher Scientific, Inc.), while other cell lines were cultured in DMEM (Gibco; Thermo Fisher Scientific, Inc.). All media were supplemented with $10 \%$ fetal bovine serum (FBS; Gibco; Thermo Fisher Scientific, Inc.) and cells were cultured at $37^{\circ} \mathrm{C}$ in a humidified atmosphere with $5 \% \mathrm{CO}_{2}$.

Reverse transcription-quantitative PCR (RT- $q P C R)$. RT-qPCR was used to determine the expression levels of HOTTIP, $\beta$-catenin and c-Myc in tissues and cells (including hFOB1.19, SaoS2, HOS, U2OS and MG63 cell lines). Total RNA was extracted from tissues ( $\geq 100 \mathrm{mg}$ ) and cells $\left(\geq 1 \times 10^{5}\right)$ using TRIzol reagent (Invitrogen; Thermo Fisher Scientific, Inc.) following the manufacturer's protocol. cDNA was synthesized using GoScript Reverse Transcription Mix, Random Primers (Promega Corporation). qPCR was performed in an ABI7500 instrument using Toyobo SYBR Green Realtime PCR Master Mix (cat. no., QPK-201; Toyobo Life Sciences). The following thermocycling conditions were used: Initial denaturation at $95^{\circ} \mathrm{C}$ for $3 \mathrm{~min}$; followed by 40 cycles of $95^{\circ} \mathrm{C}$ for $15 \mathrm{sec}$ and $60^{\circ} \mathrm{C}$ for $1 \mathrm{~min}$; finally dissociation at $60^{\circ} \mathrm{C}$ for $10 \mathrm{~min}$. $\beta$-actin was used as an internal control. Fold changes were calculated using the relative quantification $\left(2^{-\Delta \Delta \mathrm{Cq}}\right)$ method (26). The primers used were as follows: HOTTIP, forward 5'-CCT AAAGCCACGCTTCTTTG-3', reverse 5'-TGCAGGCTG GAGATCCTACT-3'; $\beta$-actin, forward 5'-TCTTCGCCTTAA TACTTGT-3', reverse 5'-AAGCCTTCATACATCTCAA-3'; $\beta$-catenin, forward 5'-CCTTTGTCCCGCAAATCATG-3', reverse 5'-CGTACGGCGCTGGGTATC-3'; c-Myc, forward 5'-TACATCCTGTCGGTCCAA-3', reverse 5'-AACTGTTCT CGCCTCTTC-3'.

Small interfering RNAs (siRNAs), overexpression plasmids and transfections. HOTTIP siRNAs and negative control (si-NC) were purchased from Shanghai GenePharma Co, Ltd. The sequences were as follows: NC siRNA, 5'-GGUGGAACA AUUGCUUUUA-3'; HOTTIP siRNA 1, 5'-AAAUUGCUC ACUAACAGUGUG-3'; HOTTIP siRNA 2, 5'-UUUUCUUGU CCCAAAAUAGAG-3'. The plasmids containing the coding sequences of the two isoforms of $\mathrm{c}-\mathrm{Myc}$ gene were constructed by PCR using KOD-plus-Ver.2 kit (KOD-211; Toyobo Life Science) and cloned into pcDNA3.1 with BamHI and HindIII as restriction enzymes. Transfections were performed using Lipofectamine $^{\circledR} 2000$ (Invitrogen; Thermo Fisher Scientific, Inc.), according to the manufacturer's instructions. Briefly, cells $\left(1 \times 10^{5}\right.$ cells/well; U-2OS and MG63 cell lines were used since HOTTIP was highly expressed in the two cell lines) were seeded into a 6-well plate and incubated at $37^{\circ} \mathrm{C}$ overnight. Prior to the transfection, the siRNA/plasmid-Lipofectamine solution was prepared by mixing $200 \mu 1$ MEM separately with Lipofectamine $(5 \mu \mathrm{l})$ or siRNA/plasmid $(2 \mu \mathrm{g})$ and then mixing the solutions together. Finally, the siRNA/plasmid-Lipofectamine solution was added into each well, and the cells were incubated at $37^{\circ} \mathrm{C}$ for $24 \mathrm{~h}$ (for plasmid) or $48 \mathrm{~h}$ (for siRNA) for subsequent experiments.

Cell Counting Kit-8 (CCK-8) assay and trypan blue staining. For CCK-8 assay, U-2OS and MG63 cells were seeded in 96-well plates $\left(5 \times 10^{4}\right.$ cells/well) and incubated at $37^{\circ} \mathrm{C}$ in a humidified atmosphere with $5 \% \mathrm{CO}_{2}$ for $12 \mathrm{~h}$. Subsequently, fresh medium containing 10\% FBS was added to the culture plate and $10 \mu$ l CCK-8 (Dojindo Molecular Technologies) reagent was added to each well at $0,24,48$ and $72 \mathrm{~h}$ and incubated at $37^{\circ} \mathrm{C}$ for another $2 \mathrm{~h}$. The absorbance was measured at $450 \mathrm{~nm}$ using a microplate reader (Molecular Devices). For Trypan blue staining, triplicates of U-2OS and MG63 cells ( $2 \times 10^{4}$ cells/well) were seeded in 96-well plates initially, then trypsinized at different time points $(0,24,36$ and $48 \mathrm{~h})$ and stained with trypan blue at room temperature for $5 \mathrm{~min}$; stained cells were counted using a hemocytometer and cell viability ([(total cells)-(blue cells)]x100\%) curves were plotted.

Wound healing assay. Cell migration ability was determined by wound healing assay. Transfected MG63 cells were seeded in 6 -well plate $\left(3 \times 10^{5}\right.$ cells/well) for $24 \mathrm{~h}$ until confluence was reached. A scratch was made using a sterile $200 \mu \mathrm{l}$ pipette tip in the central axis of the wells. The cells were washed with PBS and cultured with serum-free medium for $24 \mathrm{~h}$. At 48 or $72 \mathrm{~h}$, the migration of the cells into the scratch was observed under an inverted microscope (magnification, $\mathrm{x} 200$ ) and the distance between the edges of the wound was calculated.

Matrigel assay. Cell invasive ability was determined by Matrigel assay. Transfected U-2OS cells were seeded $\left(3 \times 10^{4}\right.$ cells/well) with medium containing $0.1 \%$ FBS in the upper chamber of an insert coated with Matrigel and allowed to migrate into the lower chamber supplemented with medium containing $10 \%$ FBS for $24 \mathrm{~h}\left(37^{\circ} \mathrm{C} ; 5 \% \mathrm{CO}_{2}\right)$. Cells that invaded through the membrane were fixed by $4 \%$ paraformaldehyde for $20 \mathrm{~min}$ and stained with $0.5 \%$ crystal violet solution for $30 \mathrm{~min}$ at room temperature. Three replicates were obtained.

Western blotting. Cellular proteins ( $\geq 1 \times 10^{5}$ cells/well; U-2OS and MG63 cell lines) were extracted by using RIPA buffer (Beyotime Institute of Biotechnology) containing phenylmethylsulphonyl fluoride (Beyotime Institute of Biotechnology). Proteins $(\sim 40 \mu \mathrm{g})$, quantified by bicinchoninic acid protein assay kit (Beyotime Institute of Biotechnology), were separated by $8 \%$ SDS-PAGE, transferred to a nitrocellulose membrane (EMD Millipore) and incubated with 5\% skimmed milk for 

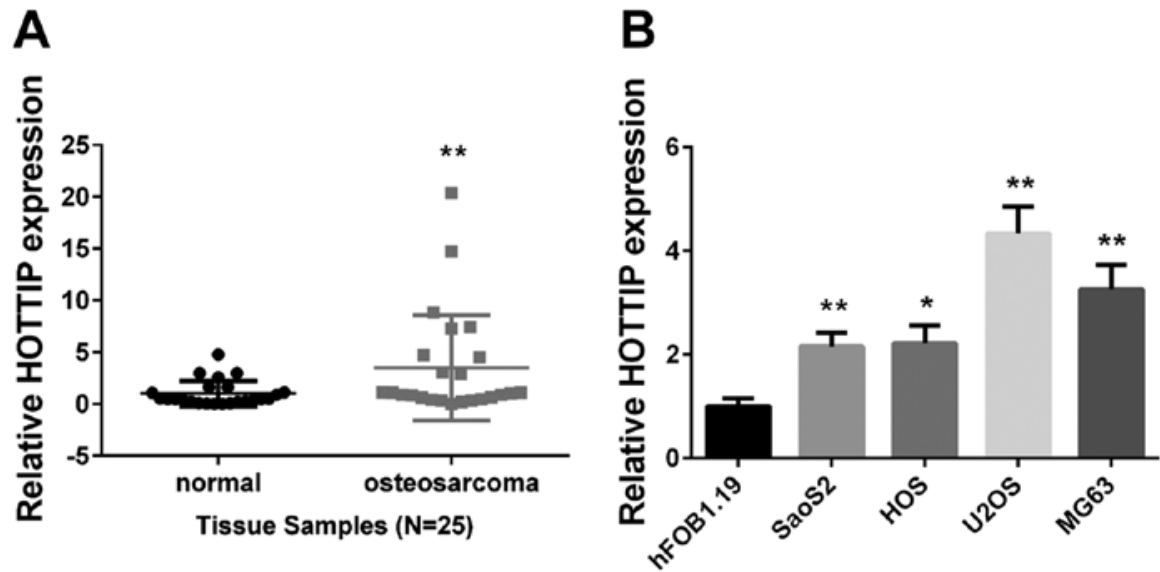

Cell Lines

Figure 1. HOTTIP is upregulated in OS tissues and cells. (A) HOTTIP expression was determined by RT-qPCR in human OS and adjacent normal tissues. (B) HOTTIP expression was determined by RT-qPCR in human normal osteoblastic hFOB1.19 cells and human OS cell lines SaoS2, HOS, U2OS and MG63. ${ }^{*} \mathrm{P}<0.05$ and $^{* *} \mathrm{P}<0.01$ vs. adjacent normal tissue or hFOB1.19 cell line. HOTTIP, homeobox A transcript at the distal tip; OS, osteosarcoma; RT-qPCR, reverse transcription quantitative-PCR.
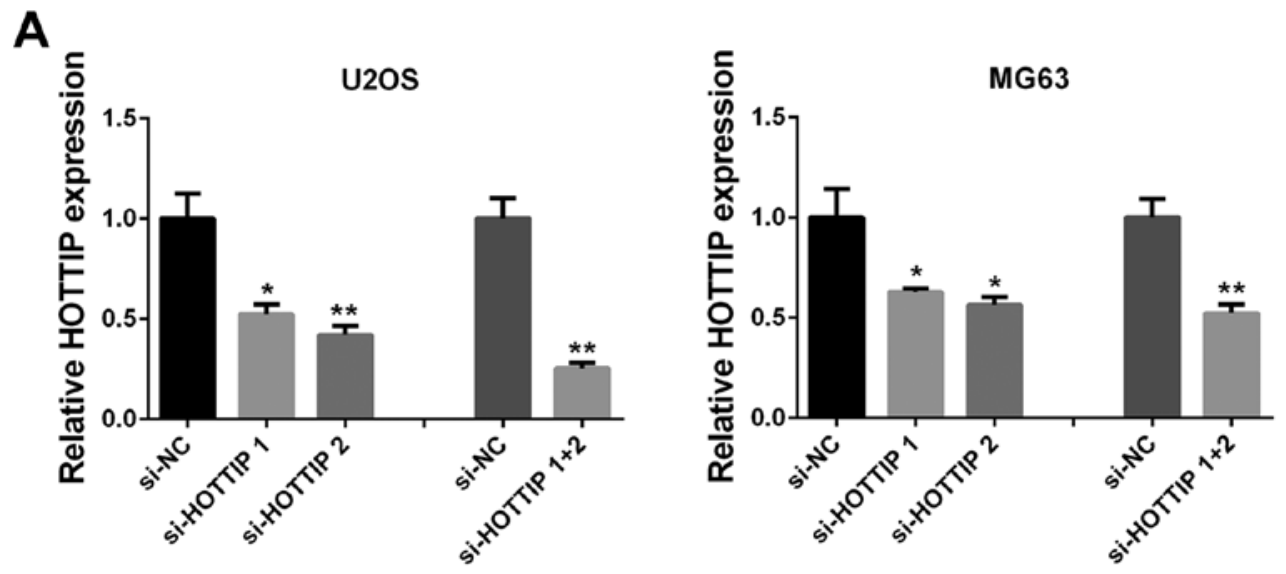

B

U-20S

MG63
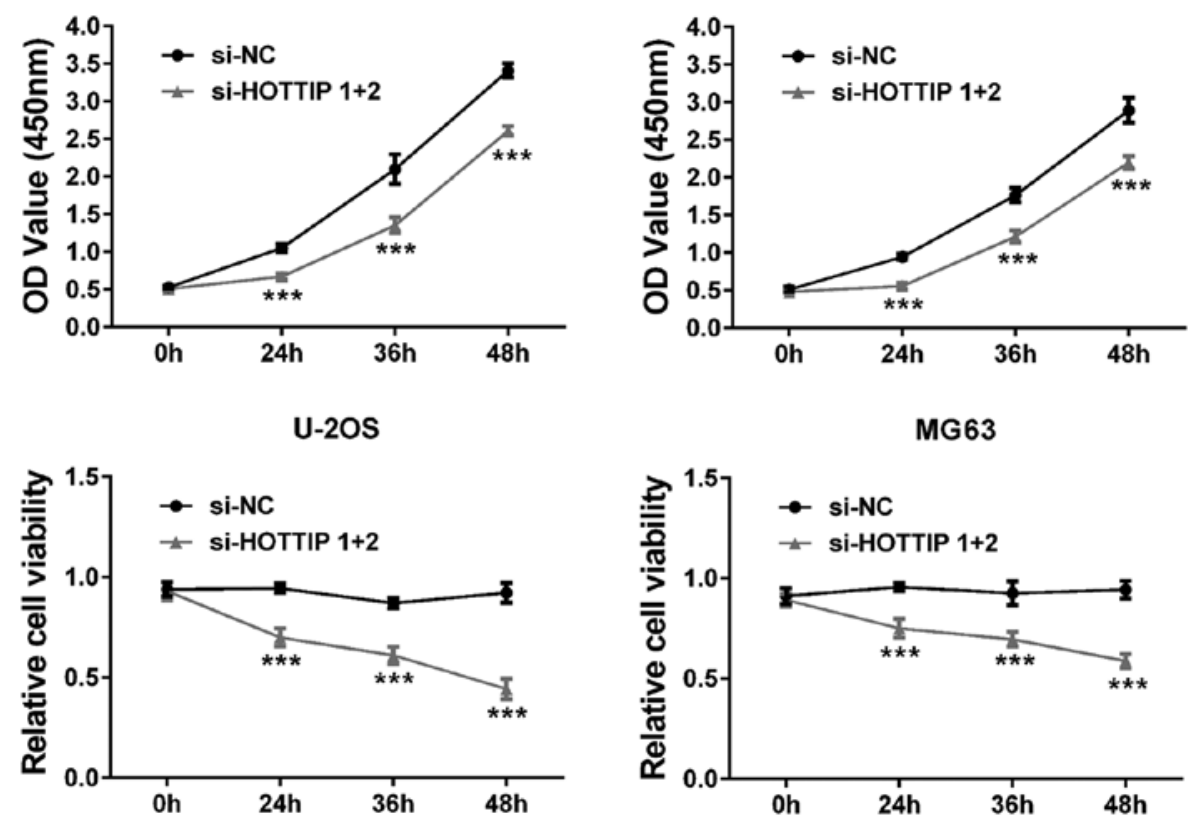

Figure 2. Knockdown of HOTTIP inhibits osteosarcoma cell viability. (A) si-HOTTIP successfully reduced HOTTIP expression levels in U2OS and MG63 cell lines. (B) Knockdown of HOTTIP reduced the viability of U2OS and MG63 cells assessed by Cell Counting Kit- 8 assay. (C) Relative cell viability determined by trypan blue staining assay. ${ }^{*} \mathrm{P}<0.05,{ }^{* *} \mathrm{P}<0.01$ and ${ }^{* * * *} \mathrm{P}<0.001$ vs. si-NC. HOTTIP, homeobox A transcript at the distal tip; NC, negative control; OD, optical density; siRNA, small interfering RNA. 


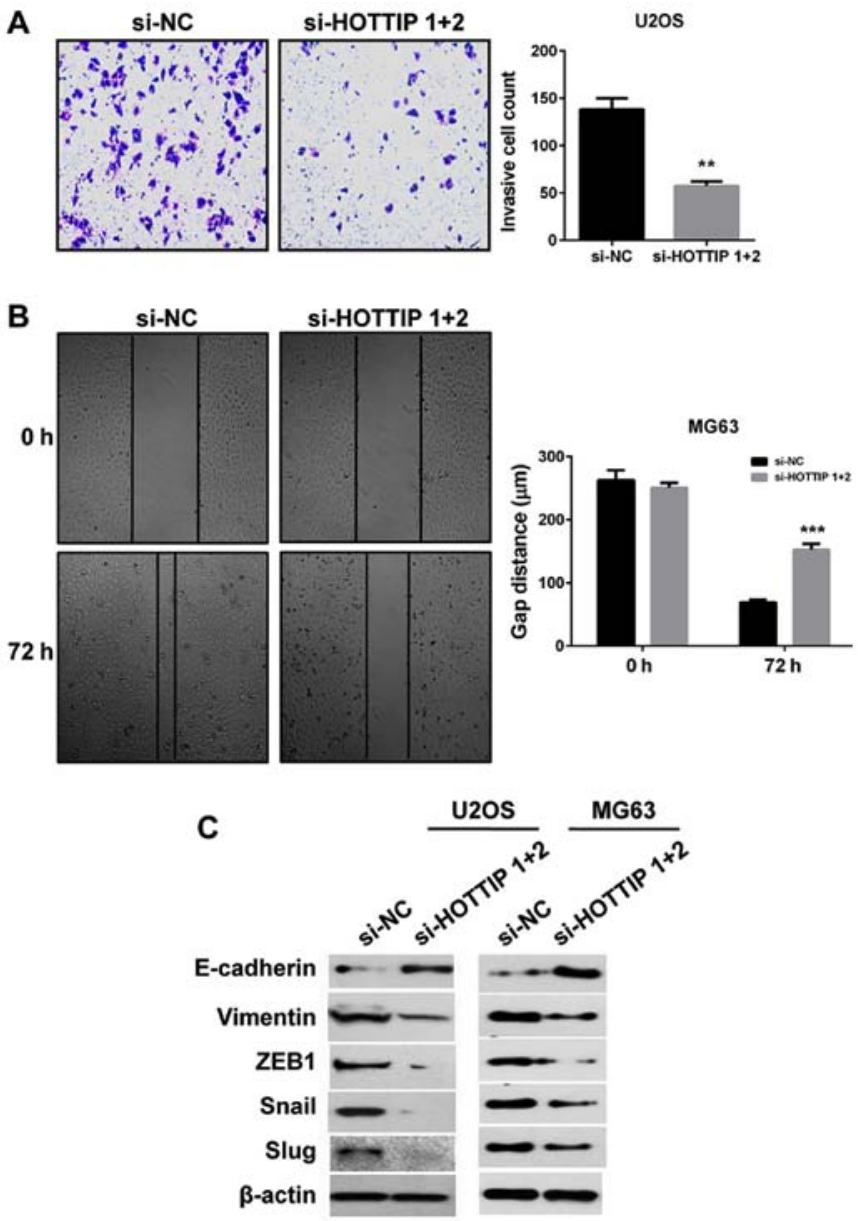

Figure 3. Knockdown of HOTTIP inhibits osteosarcoma cell invasion, migration and EMT. (A) Invasive ability of U2OS cells was reduced following siRNA knockdown of HOTTIP. Magnification, x400. (B) Migratory ability of MG63 cells was reduced following siRNA knockdown of HOTTIP. Magnification, x200. (C) Changes of EMT marker protein expression levels were determined by western blotting in U2OS and MG63 cells following knockdown of HOTTIP by siRNAs. ${ }^{* * *} \mathrm{P}<0.01$ and ${ }^{* * * *} \mathrm{P}<0.001$ vs. si-NC. EMT, epithelial-mesenchymal transition; HOTTIP, homeobox A transcript at the distal tip; NC, negative control; siRNA, small interfering RNA; ZEB1, zinc-finger E-box-binding homeobox 1.

$1 \mathrm{~h}$ at room temperature. The membranes were subsequently incubated with the following primary antibodies at a dilution of 1:1,000 at $4^{\circ} \mathrm{C}$ overnight: E-cadherin (cat. no., 3195), vimentin (cat. no., 5741), zinc-finger E-box-binding homeobox 1 (ZEB1; cat. no., 3396), Snail (cat.no., 3879), Slug (cat.no., 9585), $\beta$-catenin (cat. no., 8480), c-Myc (cat. no., 5605) and $\beta$-actin (cat. no., 4970). $\beta$-actin was used as an internal control. HRP-linked anti-rabbit IgG (cat. no., 7074; 1:1,000 dilution) was used as the secondary antibody. All antibodies were purchased from Cell Signaling Technology, Inc. Western blot bands were visualized using ECL Western Blotting Detection System (EMD Millipore).

Statistical analysis. Statistical analyses were performed using GraphPad Prism 6.0 software (GraphPad Software, Inc.). All data are presented as the mean \pm standard deviation. Experimental results were assessed using paired Student's t-test, unpaired Student's t-test or one-way analysis of variance with Dunnett's post hoc test. $\mathrm{P}<0.05$ was considered to indicate a statistically significant difference.
A

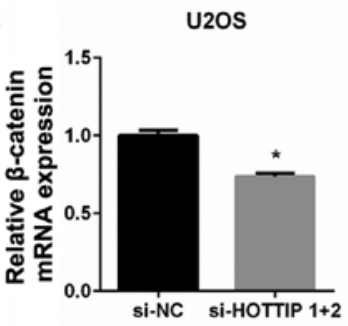

B
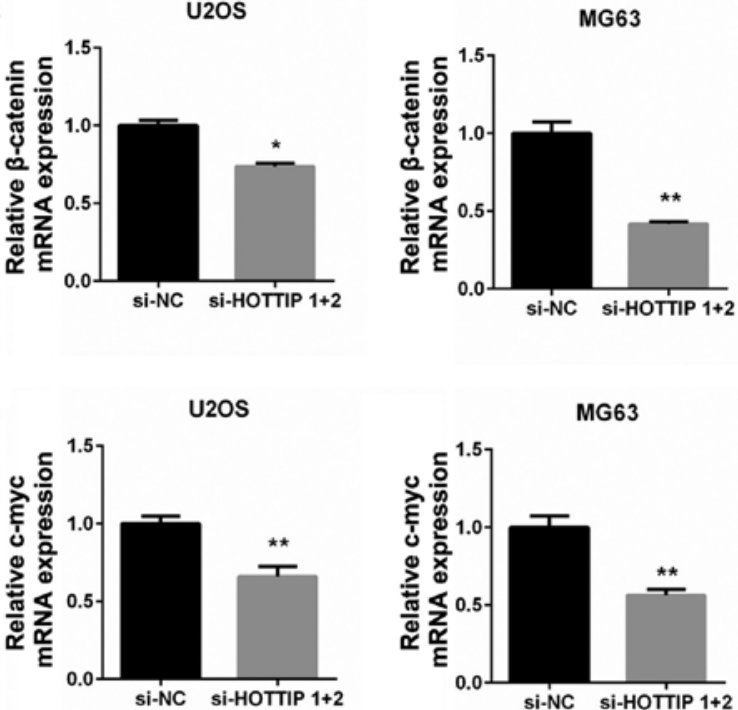

C
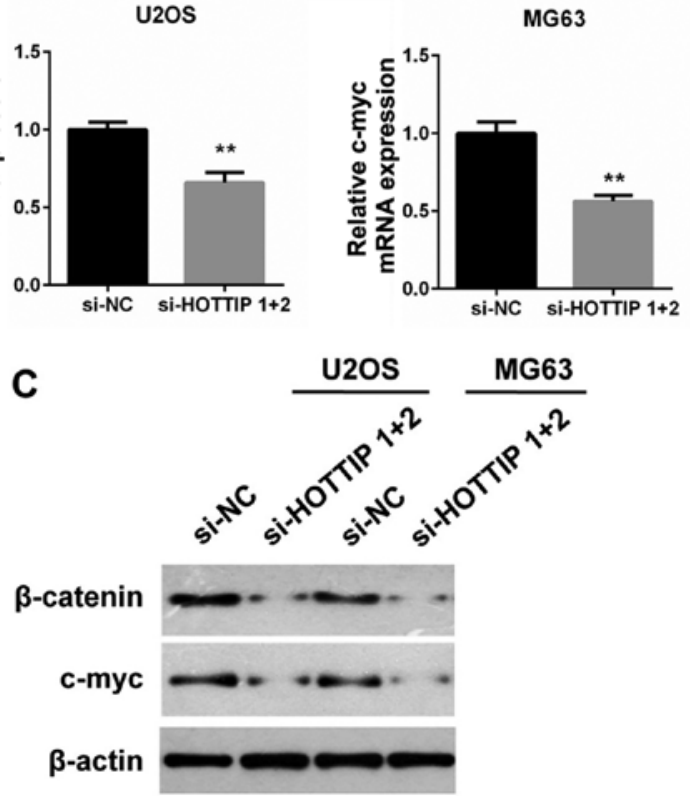

Figure 4. Knockdown of HOTTIP decreases the expression of c-Myc in osteosarcoma cells. (A) Expression of $\beta$-catenin was determined by RT-qPCR in U2OS and MG63 cells following siRNA-mediated knockdown of HOTTIP using two siRNAs. (B) Expression levels of c-Myc was determined by RT-qPCR in U2OS and MG63 cells following knockdown of HOTTIP. (C) Expression levels of $\beta$-catenin and c-Myc were determined by western blotting in U2OS and MG63 cells following knockdown of HOTTIP. ${ }^{*} \mathrm{P}<0.05$ and $^{* *} \mathrm{P}<0.01$ vs. si-NC. HOTTIP, homeobox A transcript at the distal tip; NC, negative control; RT-qPCR, reverse transcription quantitative PCR; siRNA, small interfering RNA.

\section{Results}

HOTTIP overexpression in OS tissues and cell lines. RT-qPCR was used to detect the expression levels of IncRNA HOTTIP in 25 pairs of OS tissues and adjacent non-tumor tissues. The result revealed a significant overexpression of HOTTIP in OS tissues $(\mathrm{P}<0.01$; Fig. 1A). This was in agreement with the previous reports $(23,24)$. HOTTIP expression was also analyzed in vitro; compared with the non-tumor human osteoblastic cell line hFOB1.19, HOTTIP was significantly upregulated in the four OS cell lines (Fig. 1B). The overexpression of HOTTIP suggested it may serve tumor-promoting roles in OS development.

Knockdown of HOTTIP inhibits OS cell viability, invasion, migration and EMT. siRNA-mediated silencing was used to knock down HOTTIP expression levels in two OS cell lines, U2OS and MG63, as HOTTIP was indicated to be highly expressed in these cells. Individual and simultaneous 
A

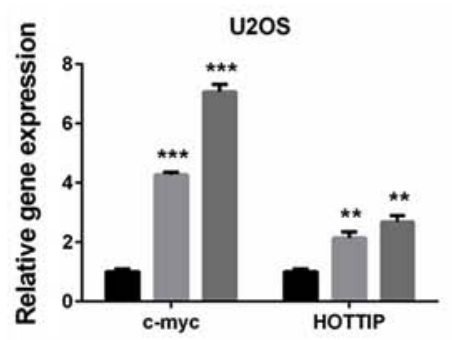

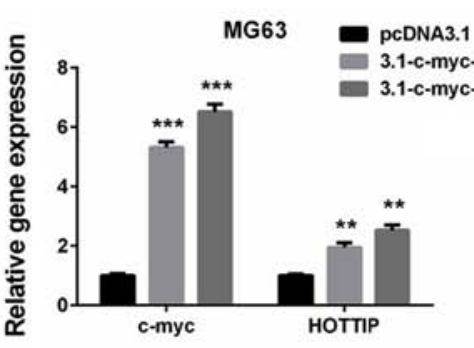

B

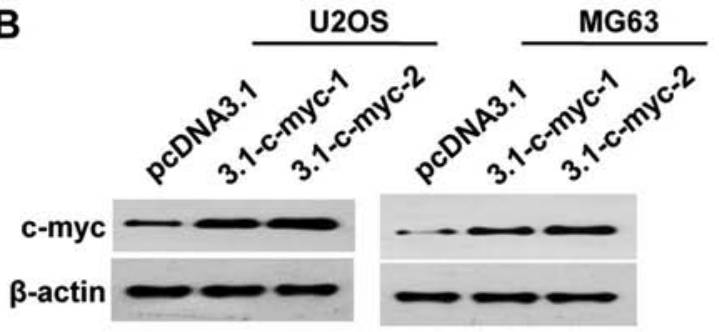

C

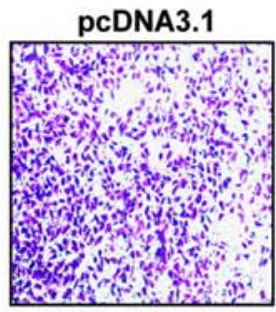

D

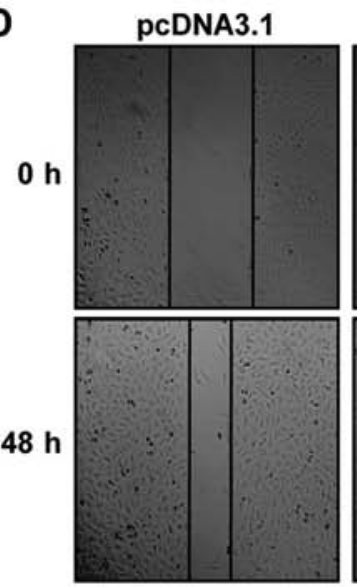

3.1-c-myc-1

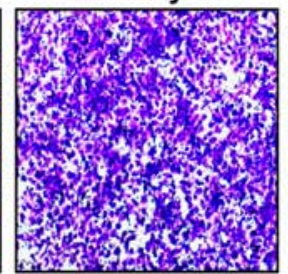

3.1-c-myc-1

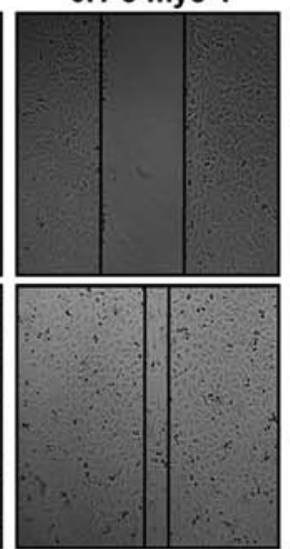

3.1-c-myc-2

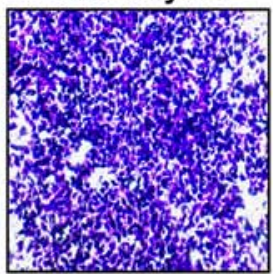

3.1-c-myc-2

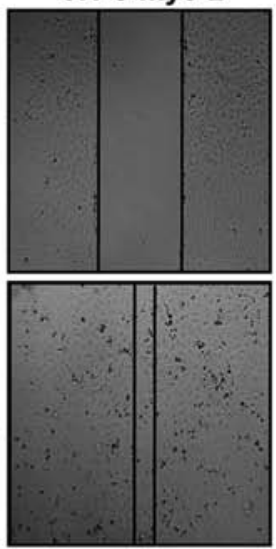

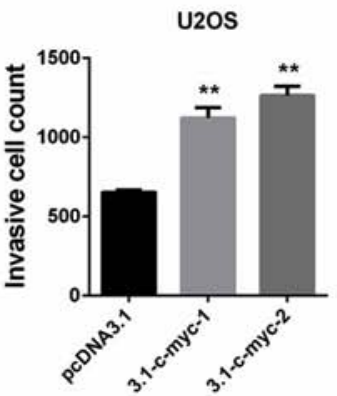

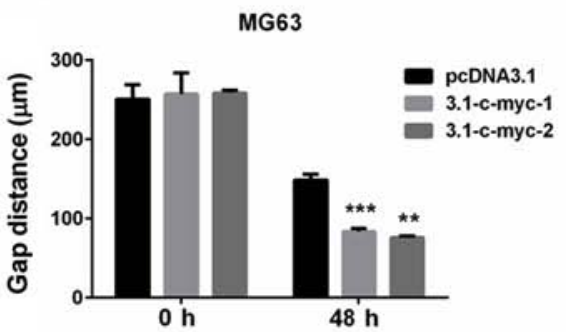

Figure 5. Overexpression of c-Myc promotes osteosarcoma cell invasion and migration by positively regulating HOTTIP. (A) Expression levels of c-Myc and HOTTIP were determined by reverse transcription-quantitative PCR in U2OS and MG63 cells following c-Myc overexpression. (B) Overexpression efficiency of c-Myc was determined by western blotting in U2OS and MG63 cells. (C) U2OS cell invasive ability was evaluated by Matrigel assay following c-Myc overexpression. (D) MG63 cell migratory ability was evaluated by wound healing assay following c-Myc overexpression. ${ }^{* *} \mathrm{P}<0.01$ and ${ }^{* * *} \mathrm{P}<0.001 \mathrm{vs}$. pcDNA3.1. HOTTIP, homeobox A transcript at the distal tip.

transfections of two siRNAs against HOTTIP successfully decreased HOTTIP expression levels in the two OS cell lines $(\mathrm{P}<0.05$; Fig. 2A); co-transfection with si-HOTTIP 1 and si-HOTTIP 2 was used in all subsequent experiments. CCK-8 assay revealed that HOTTIP knockdown notably inhibited cell viability compared with the si-NC group $(\mathrm{P}<0.001$; Fig. $2 \mathrm{~B})$. In addition, trypan blue staining also demonstrated that HOTTIP knockdown significantly reduced OS cell viability $(\mathrm{P}<0.001$; Fig. 2C).

To determine the role of HOTTIP in OS pro-metastatic processes in vitro, Matrigel and wound healing assays were performed to evaluate the invasive and migratory capacities of the cells, respectively. Due to the large size of MG63 cells and therefore their inability to pass through the holes of the Transwell, Matrigel assay was only performed in U2OS cells. Whereas for wound healing assay, MG63 cells were used since they exhibited higher migration capacity. The results demonstrated that HOTTIP knockdown inhibited cell invasion and migration compared with si-NC transfected cells
(Fig. 3A and B). Since EMT is also a key pro-metastatic process, the expression of EMT markers was detected by western blotting. Following HOTTIP knockdown, the protein expression levels of the epithelial marker E-cadherin were upregulated, whereas the protein expression levels of the mesenchymal markers vimentin, ZEB1, Snail and Slug were downregulated in two OS cell lines (Fig. 3C). These results indicated that HOTTIP may have a role in the promotion of OS invasion, migration and EMT.

Reciprocal regulation between HOTTIP and c-Myc. Based on a previous report by Li et al (24), HOTTIP activates the $\mathrm{Wnt} / \beta$-catenin pathway in OS cells. Since c-Myc is an important effector of the Wnt/ $\beta$-catenin pathway, RT-qPCR and western blotting were used to examine whether HOTTIP regulated the expression of c-Myc in OS cells. Knockdown of HOTTIP led to a decrease of $\beta$-catenin and c-Myc mRNA expression $(\mathrm{P}<0.05$; Fig. $4 \mathrm{~A}$ and $\mathrm{B})$. The decreased expression was also observed in their protein levels (Fig. 4C). Therefore, it was 
A
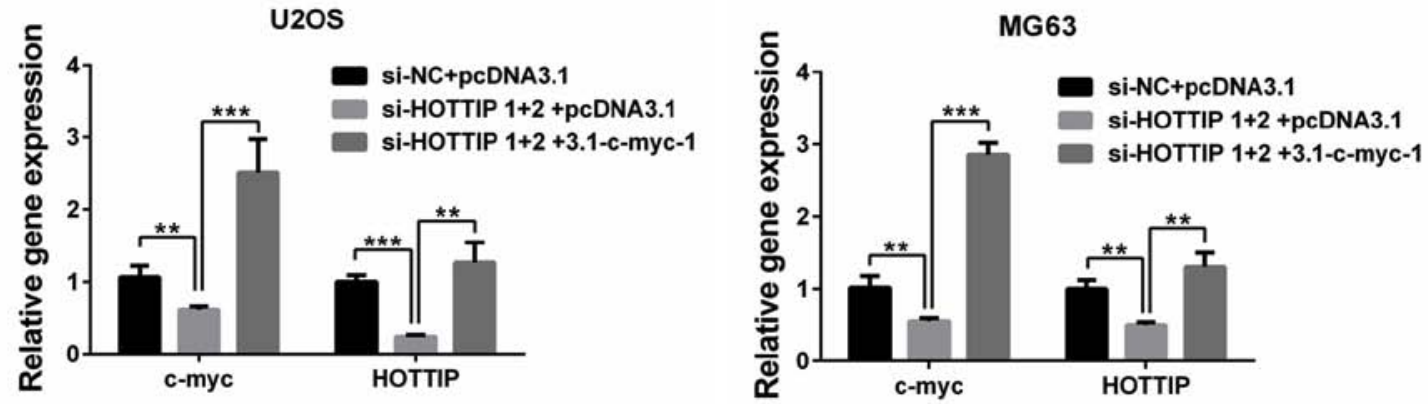

B

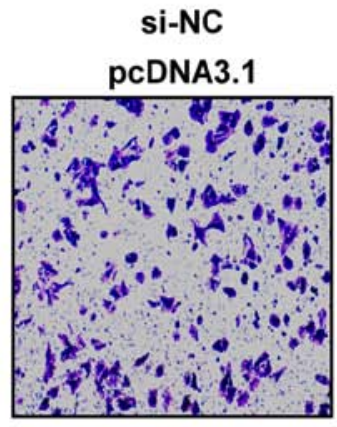

si-HOTTIP 1+2

si-HOTTIP 1+2
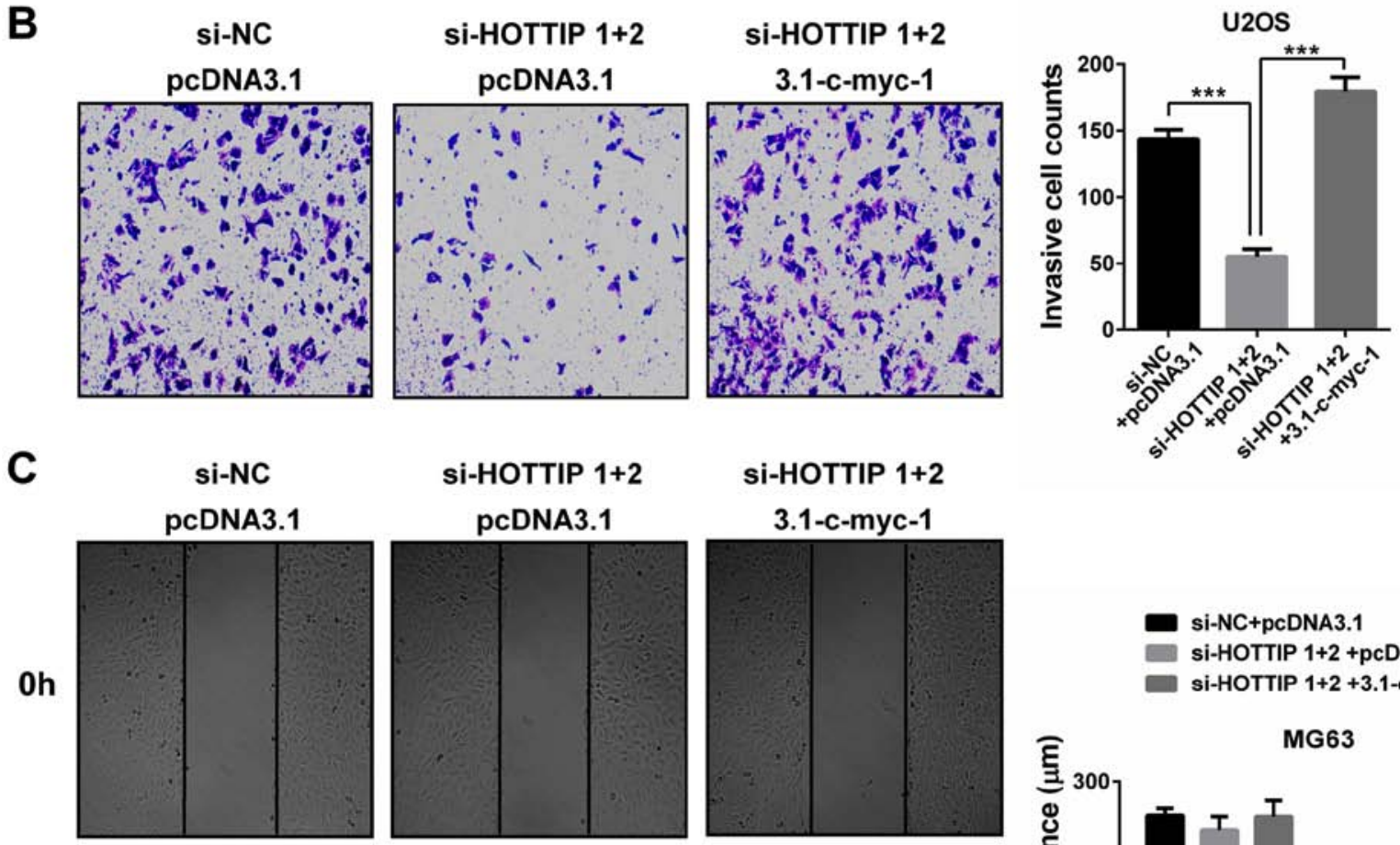

si-HOTTIP 1+2 pcDNA3.1

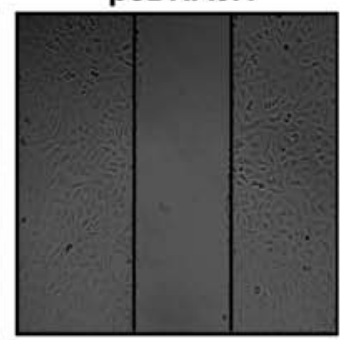

si-HOTTIP 1+2

3.1-c-myc-1
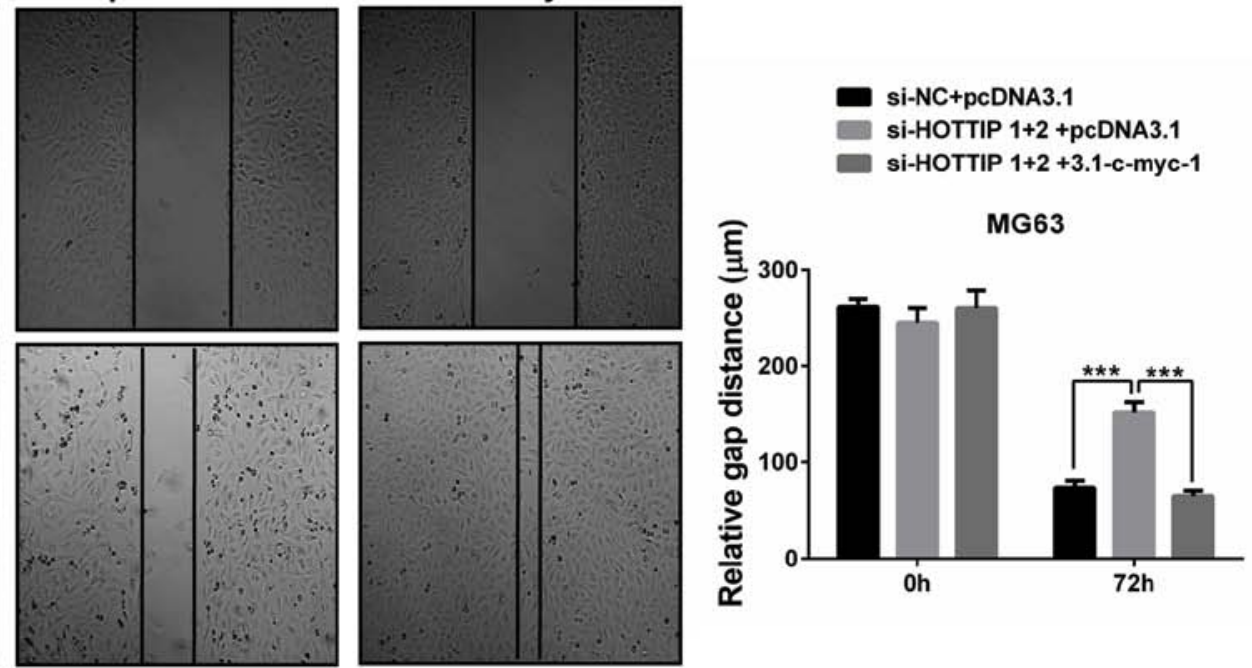

Figure 6. Restoration of c-Myc rescues the anti-migratory and anti-invasive effects of HOTTIP knockdown in osteosarcoma cells. (A) The expression levels of c-Myc and HOTTIP were determined by reverse transcription quantitative-PCR in U2OS and MG63 cells. (B) U2OS cell invasive ability was evaluated by Matrigel assay following c-Myc restoration. Magnification, x400. (C) MG63 cell migratory ability was evaluated by wound healing assay following c-Myc restoration. Magnification, $\mathrm{x} 200 .{ }^{* *} \mathrm{P}<0.01$ and ${ }^{* * * *} \mathrm{P}<0.001$ vs. si-NC + pcDNA3.1 or si-HOTTIP $1+2+$ pcDNA3.1. HOTTIP, homeobox A transcript at the distal tip. siRNA, small interfering RNA.

concluded that HOTTIP may promote c-Myc expression in OS cells. Conversely, HOTTIP was upregulated by c-Myc overexpression in the two OS cell lines. The two isoforms of c-Myc were confirmed to be overexpressed $(\mathrm{P}<0.001$; Fig. $5 \mathrm{~A}$ and $\mathrm{B})$ and increased HOTTIP expression levels $(\mathrm{P}<0.01$; Fig. 5A), compared with cells transfected with an empty vector. Furthermore, c-Myc overexpression promoted OS cell invasion and migration in vitro $(\mathrm{P}<0.01$; Fig. $5 \mathrm{C}$ and $\mathrm{D})$. These findings indicate the oncogenic role of c-Myc in OS cells, and provide a reciprocal linkage of HOTTIP and c-Myc.
Restoration of $c$-Myc in HOTTIP-silenced OS cells rescued OS cell invasion and migration. To test whether HOTTIP promoted OS cell invasion and migration by upregulating c-Myc, c-Myc was overexpressed in HOTTIP-silenced OS cells. RT-qPCR validated the overexpression of c-Myc as well as the induction of HOTTIP expression in the restoration group $(\mathrm{P}<0.01$; Fig. 6A). Furthermore, c-Myc restoration rescued OS cell invasion and migration $(\mathrm{P}<0.001$; Fig. $6 \mathrm{~B}$ and $\mathrm{C})$. These results suggested that $\mathrm{c}-\mathrm{Myc}$ may be the mediator of the oncogenic role of HOTTIP in OS cells. 


\section{Discussion}

Mainly arising from the mesenchymal cells of the long bones, OS is the most common bone malignancy in the world (1). Despite the progress on its treatment options, including surgery and chemotherapy, most patients with OS still experience recurrence and have a short overall survival time (3). Metastasis is the major cause of the unsatisfactory clinical outcome. A recent study has suggested that dysregulated expression of several IncRNAs is implicated in OS progression (16). HOTTIP is among these lncRNAs, and two reports have identified its expression and tumor-promoting activities in OS $(23,24)$. However, the role and mechanism of HOTTIP in OS cell migration, invasion and EMT remain unclear.

Overexpression of HOTTIP has been reported in a number of human cancers; with HOTTIP associated with multiple cancer-associated malignancy phenotypes and signaling pathways, in addition to contributing to cancer development (21). In the present study, higher expression of HOTTIP was confirmed in OS tissues and all cell lines compared to their matched controls. Moreover, knockdown of HOTTIP by siRNAs reduced the viability of two OS cell lines. These findings were in agreement with the previous studies on the role of HOTTIP in OS $(23,24)$.

Furthermore, the present study suggested that HOTTIP may also contribute to the aggressive phenotypes of OS. The in vitro experiments consistently demonstrated that knockdown of HOTTIP inhibited OS cell migration, invasion and EMT, which indicated the pro-metastatic activity of HOTTIP in OS. This was in agreement with previous studies, which have identified the promotion of cancer invasion and EMT by HOTTIP in gastric cancer, esophageal squamous cell carcinoma and glioma (27-29). In the first report of HOTTIP in OS by Li $e t a l$, the analysis of the association between HOTTIP expression levels and several clinicopathological features of patients with OS revealed that high HOTTIP expression was associated with distant metastasis (23). In vitro experiments from the same study demonstrated that knockdown of HOTTIP inhibited OS cell migration and invasion (23). Therefore, the results of the present study validated their findings and verified the promotion of EMT by HOTTIP in OS cells.

The relationship between HOTTIP and the Wnt/ $/$-catenin signaling pathway in OS cells has been described by $\mathrm{Li}$ et al (24). HOTTIP overexpression leads to increased expression of cyclin D1, cyclin-dependent kinase 4 and $\beta$-catenin proteins, which are the effectors of the $\mathrm{Wnt} / \beta$-catenin signaling pathway (24). The activation of $\mathrm{Wnt} / \beta$-catenin signaling by HOTTIP is associated with the pro-growth and chemoresistance roles of HOTTIP in OS cells (24). Recently, a study from colorectal cancer revealed that knockdown of HOTTIP inhibited cell proliferation and migration, and significantly suppressed the expression of glycogen synthase kinase $3 \beta, \beta$-catenin and c-Myc (30). The results of the present study demonstrated that knockdown of HOTTIP decreased the expression of $\beta$-catenin and $\mathrm{c}-\mathrm{Myc}$ at both mRNA and protein levels. In addition, c-Myc overexpression increased HOTTIP expression. Thus, HOTTIP and c-Myc may form a positive feedback loop. The reciprocal regulation between HOTTIP and c-Myc may explain the upregulation of HOTTIP in OS, as elevated c-Myc expression may determine the upregulation of
HOTTIP. Conversely, c-Myc overexpression may promote OS cell migration and invasion in vitro, which may be related to the pro-metastatic role of HOTTIP in OS cells.

In conclusion, the results of the present study demonstrated that IncRNA HOTTIP was overexpressed in OS and may facilitate migration, invasion and EMT in vitro by forming a positive feedback loop with c-Myc. However, there are still several limitations. Firstly, the oncogenic roles of HOTTIP in OS cells need to be confirmed by in vivo data in the near future. Secondly, the molecular mechanisms governing the reciprocal regulation of HOTTIP and c-Myc remain largely unclear. Finally, HOTTIP may have an impact on OS progression via other pathways. The findings of the present study support that HOTTIP may serve as a promising therapeutic target in the treatment of OS.

\section{Acknowledgements}

Not applicable.

\section{Funding}

No funding was received.

\section{Availability of data and materials}

The datasets used and/or analyzed during the present study are available from the corresponding author on reasonable request.

\section{Authors' contributions}

YT and FJ designed the study. YT performed the experiments and analyzed the data. FJ wrote the manuscript. Both authors have read and approved the final version of this manuscript.

\section{Ethics approval and consent to participate}

Ethical approval for this study was obtained from the Ethics Committee of Changhai Hospital, Second Military Medical University (Shanghai, China), and written informed consent was obtained from all patients at the initial stage of this study.

\section{Patient consent for publication}

All patients provided written informed consent for the publication of their data.

\section{Competing interests}

The authors declare that they have no competing interests.

\section{References}

1. Yang Y, Han L, He Z, Li X, Yang S, Yang J, Zhang Y, Li D, Yang $Y$ and Yang Z: Advances in limb salvage treatment of osteosarcoma. J Bone Oncol 10: 36-40, 2017.

2. Abarrategi A, Tornin J, Martinez-Cruzado L, Hamilton A, Martinez-Campos E, Rodrigo JP, González MV, Baldini N, Garcia-Castro J and Rodriguez R: Osteosarcoma: Cells-of-Origin, cancer stem cells and targeted therapies. Stem Cells Int 2016: 3631764, 2016. 
3. Meazza C and Scanagatta P: Metastatic osteosarcoma: A challenging multidisciplinary treatment. Expert Rev Anticancer Ther 16: 543-556, 2016.

4. Osasan S, Zhang M, Shen F, Paul PJ, Persad S and Sergi C: Osteogenic sarcoma: A 21st century review. Anticancer Res 36 : 4391-4398, 2016.

5. Vos HI, Coenen MJ, Guchelaar HJ and Te Loo DM: The role of pharmacogenetics in the treatment of osteosarcoma. Drug Discov Today 21: 1775-1786, 2016.

6. Bonasio R and Shiekhattar R: Regulation of transcription by long noncoding RNAs. Annu Rev Genet 48: 433-455, 2014.

7. Mercer TR, Dinger ME and Mattick JS: Long non-coding RNAs: Insights into functions. Nat Rev Genet 10: 155-159, 2009.

8. Ponting CP, Oliver PL and Reik W: Evolution and functions of long noncoding RNAs. Cell 136: 629-641, 2009.

9. Li X and Li N: LncRNAs on guard. Int Immunopharmacol 65: 60-63, 2018.

10. Zampetaki A, Albrecht A and Steinhofel K: Long non-coding RNA structure and function: Is there a link? Front Physiol 9: 1201,2018

11. Balas MM and Johnson AM: Exploring the mechanisms behind long noncoding RNAs and cancer. Noncoding RNA Res 3: 108-117, 2018.

12. Pop-Bica C, Gulei D, Cojocneanu-Petric R, Braicu C, Petrut B and Berindan-Neagoe I: Understanding the role of non-coding RNAs in bladder cancer: From dark matter to valuable therapeutic targets. Int J Mol Sci 18: pii: E1514, 2017.

13. Khorshidi A, Dhaliwal P and Yang BB: Noncoding RNAs in tumor angiogenesis. Adv Exp Med Biol 927: 217-241, 2016.

14. Wang G, Liu C, Deng S, Zhao Q, Li T, Qiao S, Shen L, Zhang Y, Lü J, Meng L, et al: Long noncoding RNAs in regulation of human breast cancer. Brief Funct Genomics 15: 222-226, 2016.

15. Li Z, Dou P, Liu T and He S: Application of long noncoding RNAs in osteosarcoma: Biomarkers and therapeutic targets. Cell Physiol Biochem 42: 1407-1419, 2017.

16. Chen R, Wang G, Zheng Y, Hua Y and Cai Z: Long non-coding RNAs in osteosarcoma. Oncotarget 8: 20462-20475, 2017.

17. Li P, Huang R, Huang T, Cheng S, Chen Y and Wang Z: Long non-coding RNA NEAT1 promotes proliferation, migration and invasion of human osteosarcoma cells. Int J Med Sci 15 1227-1234, 2018

18. Xu R, Feng F, Yu X, Liu Z and Lao L: LncRNA SNHG4 promotes tumour growth by sponging miR-224-3p and predicts poor survival and recurrence in human osteosarcoma. Cell Prolif 51: e12515, 2018

19. Chen X, Zhou Y, Liu S, Zhang D, Yang X, Zhou Q, Song Y and Liu Y: LncRNA TP73-AS1 predicts poor prognosis and functions as oncogenic lncRNA in osteosarcoma. J Cell Biochem: Sep 14, 2018 doi: 10.1002/jcb.27556 (Epub ahead of print).
20. Wang KC, Yang YW, Liu B, Sanyal A, Corces-Zimmerman R, Chen Y, Lajoie BR, Protacio A, Flynn RA, Gupta RA, et al: A long noncoding RNA maintains active chromatin to coordinate homeotic gene expression. Nature 472: 120-124, 2011.

21. Fan Y, Yan T, Chai Y, Jiang Y and Zhu X: Long noncoding RNA HOTTIP as an independent prognostic marker in cancer. Clin Chim Acta 482: 224-230, 2018 .

22. Lian Y, Cai Z, Gong H, Xue S, Wu D and Wang K: HOTTIP: A critical oncogenic long non-coding RNA in human cancers. Mol Biosyst 12: 3247-3253, 2016.

23. Li F, Cao L, Hang D, Wang F and Wang Q: Long non-coding RNA HOTTIP is up-regulated and associated with poor prognosis in patients with osteosarcoma. Int J Clin Exp Pathol 8: 11414-11420, 2015

24. Li Z, Zhao L and Wang Q: Overexpression of long non-coding RNA HOTTIP increases chemoresistance of osteosarcoma cell by activating the Wnt/ $\beta$-catenin pathway. Am J Transl Res 8: 2385-2393, 2016

25. Zhang M, Wang D, Zhu T and Yin R: RASSF4 overexpression inhibits the proliferation, invasion, EMT and Wnt signaling pathway in osteosarcoma cells. Oncol Res 25: 83-91, 2017.

26. Livak KJ and Schmittgen TD: Analysis of relative gene expression data using real-time quantitative PCR and the 2(-Delta Delta C(T)) method. Methods 25: 402-408, 2001

27. Ye H, Liu K and Qian K: Overexpression of long noncoding RNA HOTTIP promotes tumor invasion and predicts poor prognosis in gastric cancer. Onco Targets Ther 9: 2081-2088, 2016.

28. Chen X, Han H, Li Y, Zhang Q, Mo K and Chen S: Upregulation of long noncoding RNA HOTTIP promotes metastasis of esophageal squamous cell carcinoma via induction of EMT. Oncotarget 7: 84480-84485, 2016.

29. Zhang S, Wang W, Liu G, Xie S, Li Q, Li Y and Lin Z: Long non-coding RNA HOTTIP promotes hypoxia-induced epithelial-mesenchymal transition of malignant glioma by regulating the miR-101/ZEB1 axis. Biomed Pharmacother 95: 711-720, 2017.

30. Liu T, Yu T, Hu H and He K: Knockdown of the long non-coding RNA HOTTIP inhibits colorectal cancer cell proliferation and migration and induces apoptosis by targeting SGK1. Biomed Pharmacother 98: 286-296, 2018.

This work is licensed under a Creative Commons Attribution-NonCommercial-NoDerivatives 4.0 International (CC BY-NC-ND 4.0) License. 